\title{
Penerapan Teknologi Kompor Pembakaran Premix Dual Tungku Multi Nosel Dalam Upaya Peningkatan Produksi Industri Kue Balok Oma Jember
}

\author{
The Application of Technology of Premix Combustion of Dual Functions Multi Nozel in The \\ Effort to Increase Production of the Oma Jember Beam Cake Industry
}

\author{
Azamataufiq Budiprasojo ${ }^{1}$, Yuli Hananto ${ }^{1}$, Ahmad Rofi'i ${ }^{1 *}$ \\ ${ }^{1}$ Jurusan Teknik, Politeknik Negeri Jember \\ *rofii@polije.ac.id
}

\begin{abstract}
ABSTRAK
Sektor industri kuliner adalah sektor bidang usaha yang menjadi tujuan masyarakat melalui rumah industri dalam mengembangkan wirausaha. Salah satu rumah industri kecil yang eksis pada bidang kuliner adalah Industri Rumah Tangga Kue Balok Oma di Jember. Industri rumah tangga tersebut bergerak dalam memproduksi kue kekinian dan sesuai dengan selera konsumen millennial berupa kue lumer coklat dengan aneka variasi topping. Letak yang sangat strategis berada di kawasan kampus dan lintas yang dilewati oleh semua lapisan masyarakat menjadikan rumah industri kecil ini menjadi tujuan costumer dalam mencari jajanan kreatif dan kuliner bercita rasa. Dengan semakin banyak pesanan costumer yang belum didukung dengan alat kompor produksi yang masih konvensional dan tradisional sehingga tidak memberikan dampak pada peningkatan omset dan tidak terealisasinya keinginan untuk membuka outlet ataupun waralaba baru. Berdasarkan masalah tersebut, maka perlu alat kompor yang inovatif dengan menggunakan teknologi tepat guna dengan pembakaran premix dual tungku multi nosel melalui program pengabdian masyarakat.Metode: program pengabdian masyarakat di rumah industri Kue Balok Oma Jember dilakukan melalui beberapa tahapan, yaitu survey, implementasi dan evaluasi. Luaran yang ditargetkan adalah menghasilkan produk kompor inovatif, meningkatnya omset, pembukaan waralaba dan pengembangan media promosi.Hasil: setelah dilakukan kegiatan pengabdian melalui tahapan diperoleh hasil berupa produk kompor pembakaran premix dual tungku multi nosel yang dihibahkan kepada mitra, peningkatan omset dan pendapatan mitra $60 \%$ dari omset sebelumnya, dibukanya outlet baru di beberapa wilayah dan pengembangan media promosi sehingga dapat meningkatkan daya beli masyarakat dan jumlah produksi.
\end{abstract}

Kata kunci - teknologi, premix dual tungku, multi nose

\begin{abstract}
The culinary industry sector is a business sector that is the goal of the community through industrial houses in developing entrepreneurship. One of the small industrial houses that exist in the culinary field is the Oma Balok Cake Home Industry in Jember. The home industry is engaged in producing contemporary cakes and according to the tastes of millennial consumers in the form of melted chocolate cakes with various variations of toppings. A very strategic location in the campus area and the traffic that is passed by all levels of society makes this small industrial house a customer destination in finding creative snacks and culinary flavors. With more and more customer orders that have not been supported by conventional and traditional production stoves so that they do not have an impact on increasing turnover and the desire to open new outlets or franchises is not realized. Based on these problems, it is necessary to use an innovative stove using appropriate technology by burning premix dual stove multi nozzles through community service programs. Methods: community service programs at the Oma Jember Balok Cake industry are carried out through several stages, namely survey, implementation and evaluation. The targeted outputs are producing innovative stove products, increasing turnover, opening franchises and developing promotional media. Outcomes: after service activities have been carried out through stages, results are obtained in the form of a multinozzle dual stove premix combustion stove that is donated to partners, an increase in partner turnover and revenue of $60 \%$ from the previous turnover, the opening of new outlets in several areas and the development of promotional media so as to increase people's purchasing power and the amount of production.
\end{abstract}

Keywords - technology, premix dual furnace, multi nose 


\section{Pendahuluan}

Rumah Industri Kue Balok Oma adalah salah satu rumah industri yang bergerak pada sektor industry kuliner kecil yang berada di kawasan kampus dan di tengah wilayah pusat perkantoran di Kabupaten Jember. Rumah industri tersebut memberikan pelayanan pada produksi kuliner berupa menu kekinian yang memiliki kekhasan coklat lumer dengan sensasi kelembutan dan lumer di mulut saat dimakan dan tampilan yang menarik.

Berdasarkan hasil survei dan wawancara awal oleh tim pada calon mitra, diperoleh informasi bahwa jumlah produksi kue coklat yang diproduksi oleh mitra mencapai 1000 buah perhari dengan harga kue Rp 3.000,- perhari sehingga omset dari usaha perhari bisa mencapai Rp 3.000.000,- bahkan bila weekend mampu menjual hingga 1500 buah kue perhari. Dengan banyaknya hasil produksi tersebut, sesungguhnya dapat memproduksi kue lebih dari yang dihasilkan sekarang dikarenakan alat kompor yang digunakan untuk memproduksi masih konvensional dan tradisional sehingga belum mampu menghasilkan jumlah produksi kue yang lebih banyak. Kendala tersebut mendasari belum meningkatnya omset penghasilan mitra dari sebelumnya dan belum terwujudnya outlet dan waralaba baru sebagai ekspansi dari pengembangan usahanya.

Pada umumnya kompor menggunakan jenis difusi dengan api yang dihasilkan berupa api difusi yang tercipta dari percampuran bahan bakar dan udara pada waktu yang bersamaan pada sisi burner. Jenis kompor ini memiliki efisiensi rendah dan menghasilkan api yang kurang panas.

Konsep utama yang diterapkan dalam mengatasi permasalahan kurangnya efisiensi dan daya api yang kurang panas adalah dengan meniru teori pembakaran pada mesin kendaraan bermotor. Metode yang digunakan adalah dengan mencampur terlebih dahulu bahan bakar dan udara pada suatu chamber khusus sebelum burner chamber. Proses pencampuran bisa dilakukan dengan memanfaatkan suatu teorema Bernoulli yang memanfaatkan kecepatan aliran fluida untuk menghasilkan perbedaan tekanan. Perbedaan tekanan fluida udara dan bahan bakar yang terjadi dapat membuat suatu campuran yang homogen antara udara bahan bakar. Pengaruhnya adalah bila campuran dibakar akanmenghasilkan api yang besar, irit bahan bakar serta lebih panas. Pembakaran jenis ini disebut pembakaran premix dan api yang dihasilkan disebut api premix.

Dengan memanipulasi campuran bahan bakar dan udara premix dilakukan agar mampu terdistribusi dalam burner dalam bentuk droplet yang berupa partikel cairan yang sangat sangat halus maka akan didapatkan pembakaran lebih sempurna dengan api yang lebih panas lagi. Droplet bisa dihasilkan dengan memanfaatkan nosel bertekanan. Semakin banyak nosel yang diaplikasikan maka droplet yang dihasilkan semakin banyak. Pada prinsipnya kompor bekerja seperti semprotan kaleng parfum atau cat semprot. Setiap tabung gas bertekanan maka aliran gas LPG bergerak ketika katup dibuka. Aliran gas LPG masuk ke saluran dan keluar dari spuyer menuju rongga tungku. Gas ini kemudian kita bakar menggunakan pematik atau korek api. Api tidak menjalar ke saluran gas karena desain lubang-lubang kecil pada tungku dan penggunaan spuyer. Karena kecilnya lubang nosel spuyer, tekanan dan kecepatan aliran gas pada lubang spuyer sangat tinggi sehingga api tidak cukup cepat menjalar ke lubang spuyer. yang berwarna biru dengan panas yang tinggi serta kompor yang mampu memasakkan dua sisi kue secara bersamaan dengan panas yang merata karena menggunakan nosel burner tipe banyak. Selain mengaplikasikan dua teori premix dan droplet oleh nosel, kompor pembakaran premix dual tungku multi nosel ini juga dilengkapi dengan dua tungku atas dan bawah untuk menjamin kue yang akan matang secara bersamaan pada sisi atas dan sisi bawah.

Berdasarkan permasalahan dan teori yang diterapkan, maka melalui program pengabdian masyarakat dilakukan terapan langsung teknologi melalui kompor pembakaran premix dual tungku multi nosel untuk meningkatkan produksi pada Industri Rumah Tangga Kue Balok Oma Jember.

\section{Target dan Luaran}

Target yang diusahakan pada kegiatan pengabdian masyarakat melalui pada mitra Rumah Industri Kue balok Oma Jember adalah 
produk kompor pembakaran premix dual tungku multi nosel yang dihibahkan pada mitra, peningkatan omset yang dihasilkan dari penggunaan kompor yang dihibahkan, dibukanya outlet dan waralaba baru sebagai pengembangan produksi dan meningkatnya media promosi. Luaran yang diberikan pada program pengabdian kepada masyarakat antara lain; produk teknologi tepat guna berupa kompor pembakaran premix dual tungku multi nosel, artikel pada jurnal pengabdian, video kegiatan, foto kegiatan, poster pengabdian, artikel pada media nasional, invited speaker pada seminar dan jurnal prosiding pengabdian politeknik negeri Jember.

\section{Metodologi}

Metode pelaksanaan program pengabdian masyarakat pada dilakukan melalui beberapa tahap, antara lain:

\subsection{Tahap Survei}

Kegiatan yang dilakukan antara lain mengidentifikasi dan pengumpulan data mitra, membuat rancangan produk, belanja komponen produk dan alat pendukung, mendesain komponen berdasarkan rancangan, pengujian perfoma produk, adjustment dengan kondisi lapang dan monitoring teknis berkala pada produk.

\subsection{Tahap Implementasi}

Kegiatan yang dilakukan antara lain menentukan tempat pelatihan/ pendampingan dan persiapan bahan dan alat produksi di lokasi mitra, sosialisasi pelatihan dan pendampingan akan produk beserta manfaatnya ke dalam sebagai bagian proses produksi.

Untuk meningkatkan kemampuan produksi secara mandiri dilakukan monitoring berkelanjutan terhadap keterampilan dan implementasi kegiatan produksi dalam bentuk kunjungan lapang atau laporan berkala.

Kegiatan implementasi juga terdiri atas fabrikasi, pelatihan dan pendampingan serta pengembangan rencana waralaba oleh mitra.

\subsection{Tahap Evaluasi}

Kegiatan evaluasi merupakan program pertanggungjawaban dan penjalinan kerja sama berkelanjutan.

Kegiatan evaluasi dilakukan dengan mengumpulkan komponen-komponen luaran yang dibutuhkan, menjalin kerja sama dan komunikasi dengan pihak mitra.

\section{Pembahasan}

Pelaksanaan kegiatan pengabdian kepada masyarakat di Rumah Industri Kue Balok Oma Jember dengan tahapan-tahapan yang dilakukan diperoleh hasil sebagai berikut:

\subsection{Proses tahap survey}

Pada tahapan survey terlebih dahulu dilakukan pengamatan dan wawancara secara langsung pada mitra untuk mengetahui bahan yang akan digunakan pada proses produksi kue, panas yang diperlukan, batasan panas dengan menentukan temperature tingkat kematangan kue serta kapasitas produksi dari kue yang diinginkan. Berdasarkan hasil survey, maka dihitung kebutuhan panas yang diperlukan dalam proses produksinya sekaligus mempertimbangkan sumber bahan bakar yang tepat dan murah untuk mensuplay panas yang dibutuhkan. Selanjutnya dilakukan perhitungan lanjutan mengenai berapa banyak debit bahan bakar yang dibutuhkan serta bentuk nosel yang tepat untuk mengakomordir supply bahan bakar yang dibutuhkan pada api pembakaran kompor. Selanjutnya dilakukan dengan mendesain gambar teknik dari kompor yang diharapkan untuk keperluan fabrikasi.

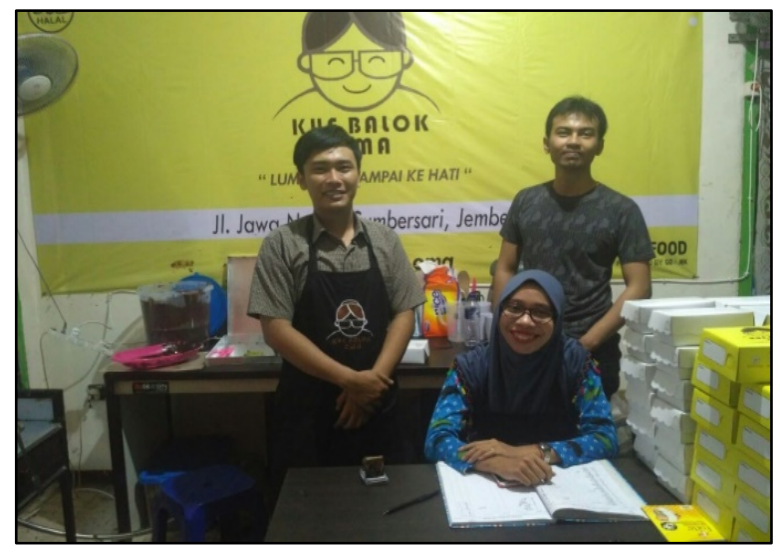

Gambar 1. Survei dan wawancara pada mitra 


\subsection{Hasil pada tahapan implementasi}

Setelah dilakukan perhitungan yang matang berdasarkan kebutuhan mitra dengan mempertimbangkan aspek teknis dan perhitungan bahan, maka selanjutnya dilakukan fabrikasi dengan memproduksi kompor sesuai dengan gambar teknik yang sebelumnya telah dibuat oleh tim.

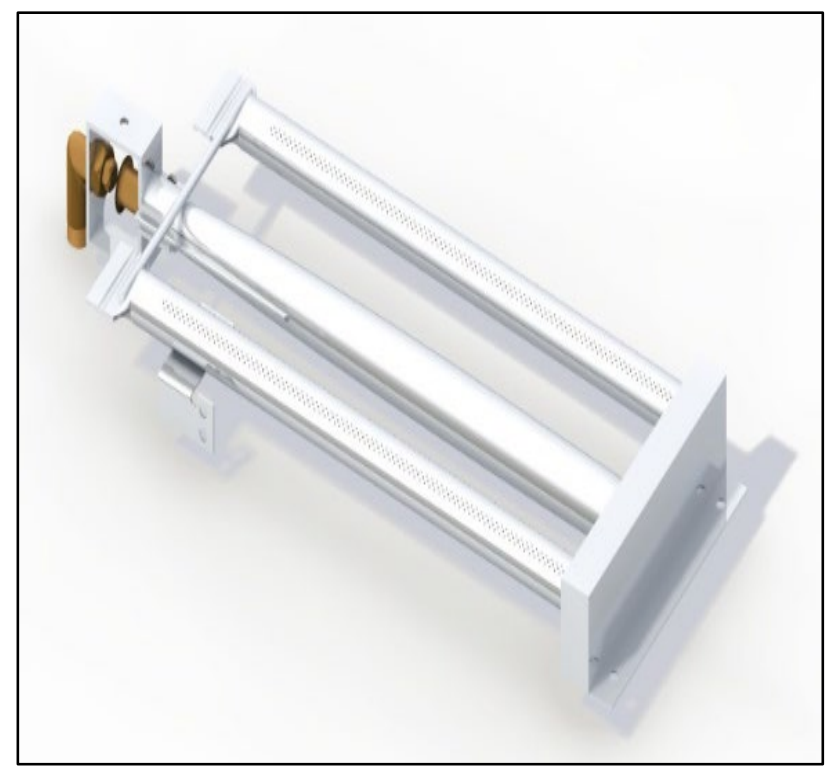

Gambar 2. Desain premix gas flame burner dengan multi nossel

Pada proses fabrikasi juga dilakukan monitoring langsung untuk memastikan produk yang dihasilkan sesuai dengan pesanan dan kebutuhan.

Pada proses fabrikasi, komponen utama adalah katup, spuyer, tungku, pipa saluran gas, pematik otomatis, saluran gas tambahan dan katup cut off. Terdapat beberapa mekanisme yang akan diberikan yaitu auto ignation (pematik api otomatis) dan penyemburan gas, pematik serta penutupan gas secara cepat. Ketiga langkah mekanik tersebut terintegrasi dalam pemutar katup gas.

Selama proses fabrikasi, dilakukan pemantauan secara langsung dengan tujuan untuk memantau secara langsung, baik proses maupun teknik yang digunakan agar sesuai dengan pesanan dan disesuaikan dengan gambar teknik yang disajikan. Setelah proses fabrikasi selesai dan alat produksi berupa kompor telah siap yang digunakan, maka langkah selanjutnya adalah menguji perfoma produk secara real serta adjustment agar cocok dengan kondisi lapangan.

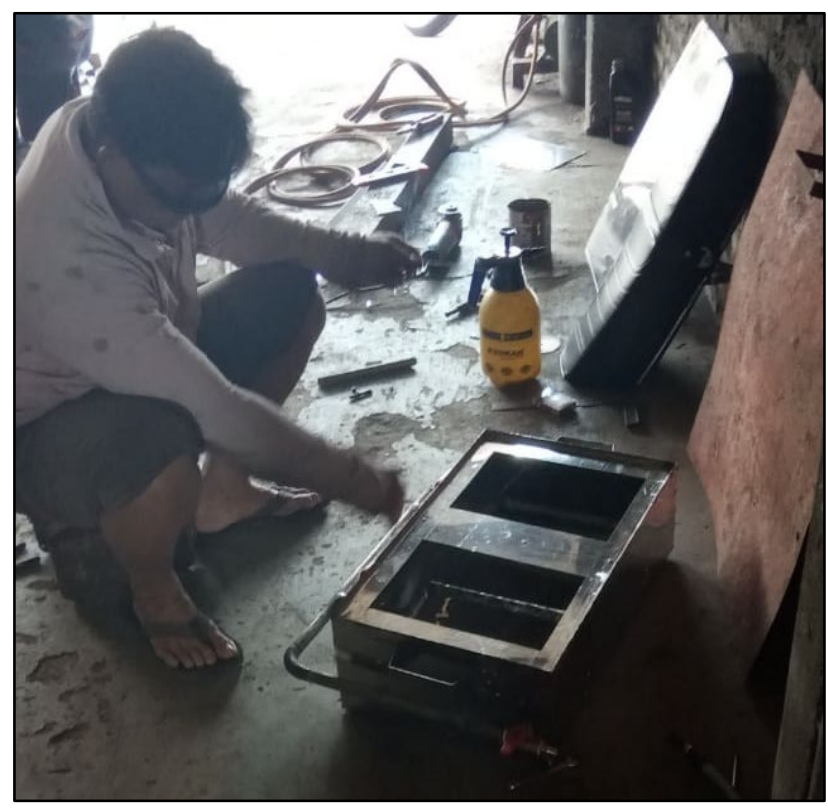

Gambar 3. Pematauan proses fabrikasi

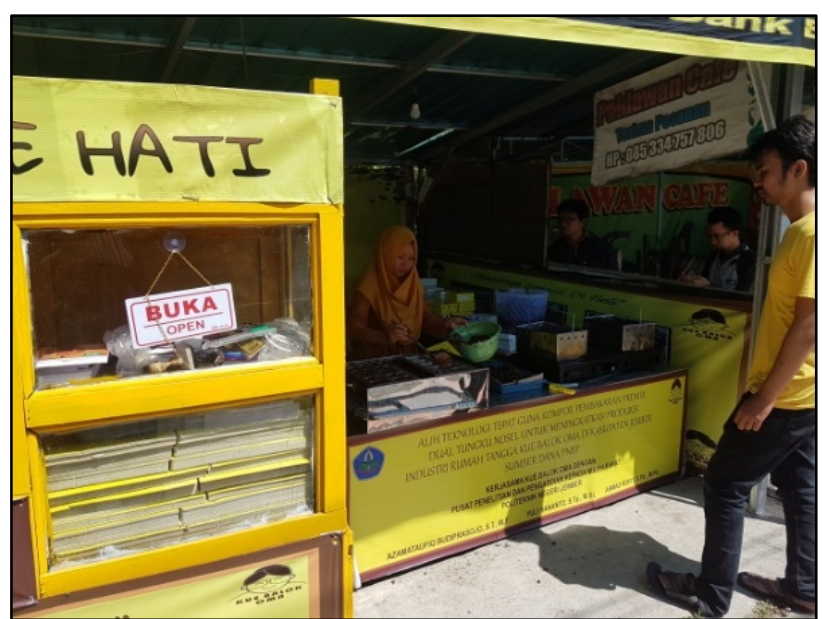

Gambar 4. Uji perfoma dan adjustment produk

Dengan proses pengujian perfoma dan adjustment produk dapat diketahui kecocokan kompor dengan kondisi lapangan., ketepatan konsep dengan desain yang diharapkan. Berdasarkan uji perfoma yang telah dilakukan diperoleh bahwa kompor pembakaran premix dual tungku multi nosel yang telah dibuat telah sesuai dengan perfoma yang diharapkan oleh mitra dan tim pengusul yang mendesain. Berdasarkan hal tersebut, maka kompor yang telah diuji telah siap dioperasikan.

Langkah selanjutnya adalah memberikan pelatihan sekaligus pendampingan pada mitra 
tentang cara pengoperasian kompor beserta cara perawatan secara teknis. Pelatihan dan pendampingan yang dilakukan secara langsung pada mitra bertujuan agar mitra dapat mengoperasikan sendiri alat produksi yang dihasilkan.

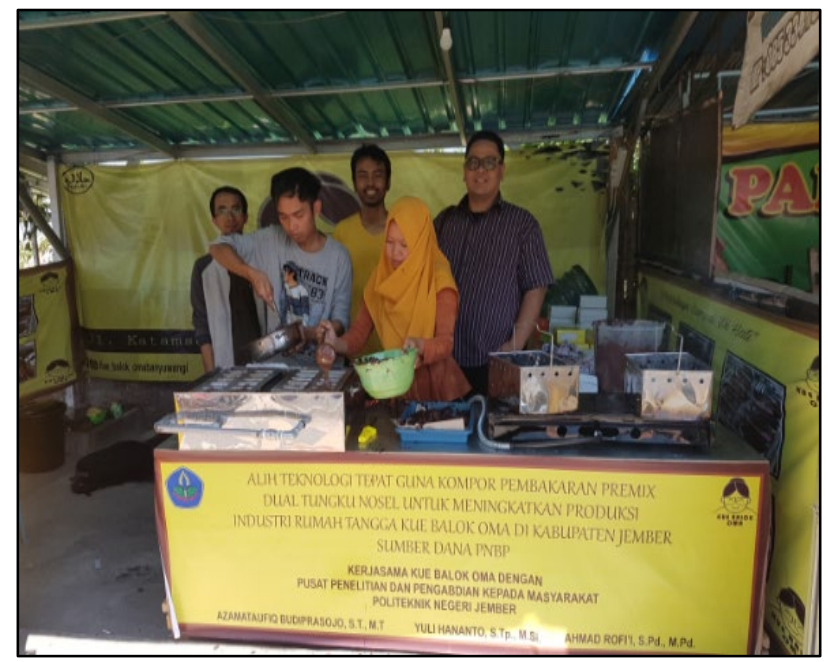

Gambar 5. Proses pelatihan dan pendampingan

Untuk pengembangan lebih lanjut dilakukan pendampingan dalam proses pembukaan outlet-outlet baru serta usaha pengembangan waralaba baru. Salah satu yang dilakukan bersama mitra adalah meningkatkan kreasi promosi, baik secara online maupun pamphlet sehingga dapat dikenal oleh masyarakat dan kalangan pebisnis.

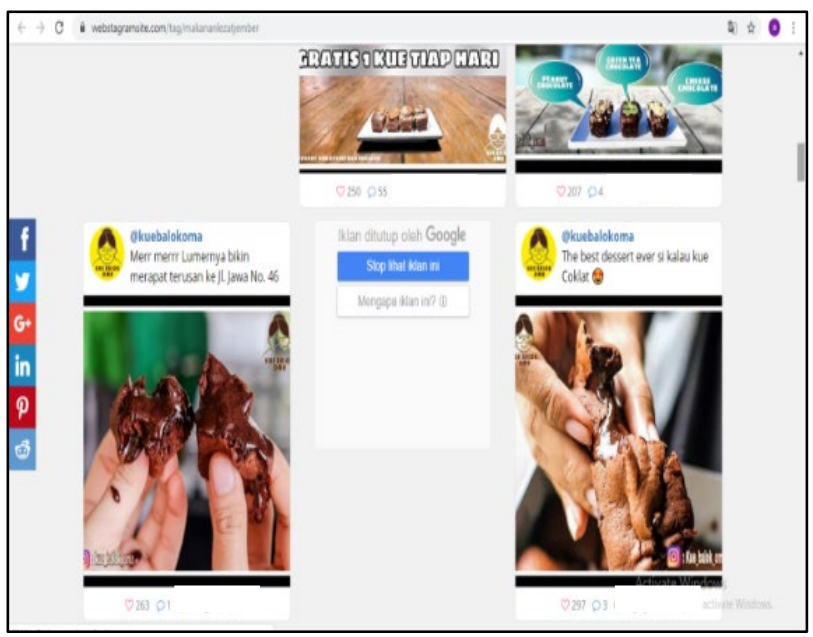

Gambar 6. Media promosi kue balok oma

\subsection{Evaluasi}

Tahap evaluasi adalah tahapan yang dilakukan untuk mengetahui hasil yang dapat dicapai selama proses kegiatan pengabdian dengan menyesuaikan pengaruh produk yang telah dihibahkan dan tahapan yang telah diselesaikan dengan kebutuhan mitra. Berdasarkan hasil pengamatan dan wawancara secara langsung dengan mitra diperoleh informasi dan hasil bahwa dengan adanya produk kompor pembakaran premix dual tungku multi nosel yang digunakan dalam produksi kue coklat lumer telah menghasilkan jumlah produksi yang lebih banyak dengan tingkat kematangan yang optimal dan waktu yang lebih singkat dari sebelumnya. Hal tersebut mempengaruhi juga dengan meningkatnya jumlah omset yang diperoleh mitra hingga mencapai 60\% lebih banyak dari omset sebelumnya. Pencapaian tersebut sangat membuat mitra sangat puas dan senang. Dengan promosi dan jumlah costumer yang sudah semakin banyak, maka selanjutnya mengarah pada pembukaan outlet baru dengan menggunakan produk yang telah dihibahkan tim pada mitra. Outlet dan waralaba baru yang dibuka antara lain, Ambulu, Banyuwangi, Lumajang dan proses pembukaan di kota Sidoarjo.

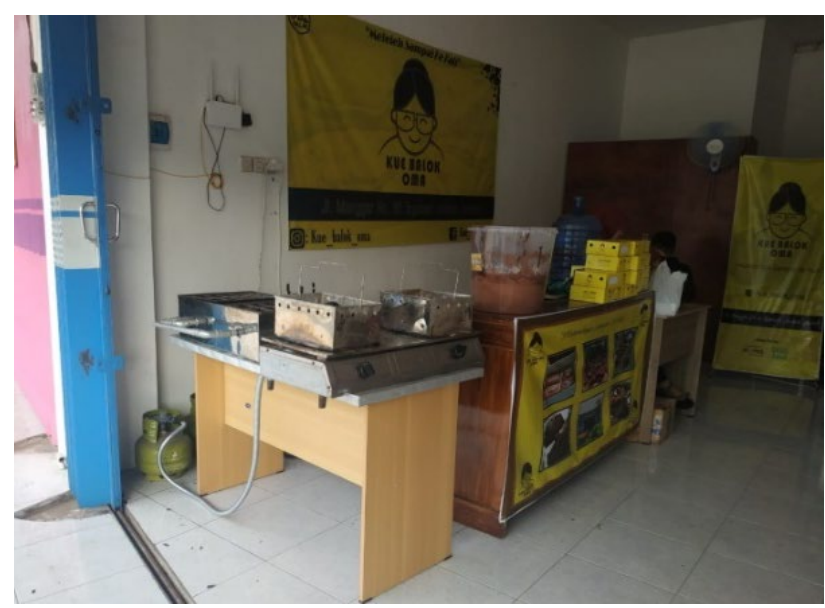

Gambar 7. Outlet Baru di Lumajang

\section{Kesimpulan}

Melalui penerapan kompor pembakaran premix dual tungku multi nosel yang digunakan oleh rumah produksi kue balok oma di Jember dapat meningkatkan jumlah produk kue dan omset yang diperoleh meningkat signifikan sebesar naik $60 \%$ dari omset sebelumnya. Dengan meningkatnya jumlah produksi dan didukung promosi yang kreatif, maka dapat memberikan dampak pada banyaknya 
masyarakat yang mengenal produk kue coklat lumer produksi rumah produksi kue balok oma Jember. Dengan telah berkembangnya produk dan promosi, maka mitra membuka outlet-outlet baru di empat daerah, yaitu Ambulu, Banyuwangi, Lumajang dan Sidoarjo. Penerapan ilmu pengetahuan dan teknologi melalui program pengabdian masyarakat sangat membantu masyarakat, terutama masyarakat industri kecil untuk meningkatkan pendapatan dan hajat hidup masyarakat.

\section{Ucapan Terima Kasih}

Dengan terselesaikannya dari proses hingga akhir kegiatan pengabdian kepada masyarakat, tim mengucapkan terima kasih yang tak terhingga pada Lembaga Penelitian dan Pengabdian Masyarakat (PPPM) Politeknik Negeri Jember yang telah memberikan bantuan dana melalui pendanaan PNBP tahun 2019.

\section{Daftar Pustaka}

[1] ANAM, Choiri, 2018. Pengaruh Pembakaran Premix Dan Non Premix Pada Meso-Scale Combustor Stainless Steel Terhadap Flammability Nyala Butana. $\mathrm{PhD}$ Thesis. University of Muhammadiyah Malang.

[2] BUDIPRASOJO, Azamataufiq, 2007. ; Karakteristik Pembakaran Api Difusi Pada Pembakaran Difusi Kerosene Udara . Rekayasa Mesin, 5.1: pp. 5-8

[3] HARYANTO, Haryanto; HIDAYATI, Baiti. 2018 Design Thermal Showcase Kue. Petra: Jurnal Teknologi Pendingin dan Tata Udara, 5.1: pp. 14-24.

[4] PRASMAYOBI, Urip. 2016. Studi Kekuatan Bending Dan Kekerasan Pada Pengelasan Aluminium Dengan Menggunakan Las Smaw (Shielded Metal Arc Weling). Enthalpy, 1.01 